- A process for training staff about carer assessment/support

- Available time/workload capacity for carer assessment/support

- Support from senior managers

- Role models/champions

- Pathways for communication about carer assessment/support

- Procedures for monitoring/auditing processes and outcomes of carer assessment/support.

Conclusions Comprehensive, person-centred carer support requires radical change, at different organisational levels. Carers' fit within service provision also urgently needs clarification. Our ten recommendations outline necessary building blocks to achieve this change.

\section{P-263 EXPLORING THE EXPERIENCE OF CARERS OF PALLIATIVE AND END OF LIFE PATIENTS}

Hollie Quaye, Giovanna Cruz. Hospice Isle of Man, Strang, Isle of Man

\subsection{6/bmjspcare-2018-hospiceabs.288}

Background Informal carers are vital in caring for palliative and end of life care (EoLC) patients and need to be adequately supported. Hospice Isle of Man sought to understand the unique carer experience and identify areas for service development.

Aims To identify the support carers access and value; the factors that assist or hinder accessing support; and to understand carer wellbeing.

Methods Using a mixed methods study design, a survey was developed based on carer reported outcome measures (Michekls et al., 2016). Data were collected on demographics and domains of the carer experience. Surveys were distributed by clinical staff to carers of patients on their case-loads between November 2017 and February 2018. We calculated frequencies for multiple-choice questions and conducted thematic analyses on qualitative responses.

Results A total of 44 carers returned the survey. The average age of carers was $58.0 \pm 17.1$ years, ranging between 7 to 84 years and $66 \%$ were female. A large proportion (68\%) felt 'out of control' since their loved one's illness. Qualitative analyses highlighted themes of feeling 'dictated to by the illness' and having 'no free time'. Half of carers received 'some' or 'little' support from their family and friends. Services provided 'some' assistance to $61 \%$ of the sample, 'a lot' to $32 \%$ and 'a little' to 7\%. Carers valued responsiveness, access to out of hours, information and reassurance. Analyses revealed difficulties in asking family for support and found practical support from external agencies to be vital. Despite these challenges, $57 \%$ of carers described the role as fulfilling.

Conclusion Carers primarily rely on services, and not families, for support. Service strategies need to recognise that although carers face challenges, they also find fulfilment and they need to support carers in ways to mitigate the feelings of loss of control.

\section{P-264 MEDICAL REVALIDATION PROCESSES IN A UK HOSPICE: EXPERIENCE FROM PHYLLIS TUCKWELL HOSPICE CARE}

Nick Dando, Cate Seton-Jones. Phyllis Tuckwell Hospice Care, Farnham, UK

10.1136/bmjspcare-2018-hospiceabs.289
Introduction Phyllis Tuckwell Hospice Care (PTHC) is an independent hospice and a Designated Body (DB) for medical revalidation. We will outline the approaches taken at PTHC to assure and improve the quality of the medical appraisal process in a voluntary hospice.

Quality assurance processes

Individual appraisals

- The Responsible Officer (RO) reads every doctor's appraisal in its entirety The RO also works closely with the Director of Patient Services who reviews all complaints and incidents. Feedback and learning is shared by the Director of Patient Services and incorporated into medical appraisal, providing further oversight of doctor's practice.

\section{Appraiser support}

- The work of the appraisers is supported by a clear job description

- All appraisees provide feedback on their appraiser which is collated by the RO and fed back as part of appraiser development

- PTHC appraisers also undertake appraisals for doctors from a local NHS Trust. This arrangement maintains and enhances the skills of the appraisers.

Organisational oversight and external review

- An appraisal quality audit was undertaken in 2017. The results demonstrated good compliance with appraisal requirements supported by evidence of reflection from the doctor and the appraiser

- Prior to revalidation, appraisal paperwork is reviewed by a Revalidation Decision Making group. This provides assurance for robust revalidation recommendations

- The appraisal system was externally assessed through a Higher Level Responsible Officer Quality Review in January 2018. The report highlighted a range of examples of good practice including strong support from the CEO and Board of Trustees.

Conclusion The model of medical appraisal developed at PTHC demonstrates that a voluntary-funded hospice can deliver a robust revalidation process within a supportive appraisal environment. The quality assurance process has been developed and implemented without an expensive electronic database or extensive team of staff, which is essential for a cost-conscious charitable organisation.

\section{P-265 TRANSFORMING HOSPICES AND PREPARING NURSES: HOW DO THEY 'FIT' TOGETHER?}

Sue Griffith. Farleigh Hospice, Chelmsford, UK

10.1136/bmjspcare-2018-hospiceabs.290

Recent publications demonstrate that pre-registration nurses are currently insufficiently prepared for end of life care (Croxon, Deravin, Anderson, 2018). Although it can be assumed that hospice nurses feel prepared, little is currently known about how they have become prepared (National Council for Palliative Care, 2016).

Aim To investigate hospice nurses' experiences of how they have become prepared for end of life care.

Method A classic Grounded Theory method was used, ensuring that no pre-conceptions influenced the findings (Glaser \& 
Strauss, 1967). Seventeen individual interviews, and one focus group of seven, were conducted to gather data. Constant comparison of the findings and analysis was conducted until theoretical saturation was reached (Glaser \& Strauss, 1967). Findings were presented to the individuals involved in the focus group, and to experts in the field, for validation (Lincoln \& Guba, 1985).

Results Analysis of the findings revealed that nurses felt they had become prepared through a feeling of 'fitting' with their workplace, colleagues and patients, through a shared ideal way to care for people at end of life. Comparison of findings with the literature, identified that the Person/Environment Fit (PEF) theory (Edwards \& Billsberry, 2010) could be used to conceptualise these findings. According to PEF theory, people choose the environment that they feel fits their vocational ideals, as well as where they fit in with the organisation's philosophy, their work group, job role and other individuals in the workplace (Edwards \& Billsberry, 2010). However, as hospices evolve rapidly to ensure accessibility to more patients and families than ever before (Mathew, Gray \& Thomas, 2018), participants commented on the changing work environment. People who felt a strong feeling of 'fit' on joining the hospice, do not always feel that fit is still there.

Conclusion As hospices continue to transform from a 'Rolls Royce' service for the minority, into a more modest style for all (Mathew, Gray \& Thomas, 2018), the findings of this study demonstrate that, during transformation, hospices may need to take measures to maintain an 'ideal' way of caring, that people feel fits their vocational aspirations.

\section{P-266 FROM NOVICE TO EXPERT IN PALLIATIVE CARE: A NEW ZEALAND EXPERIENCE}

Victoria Thompson, Kendra Ellis. Harbour Hospice, Auckland, New Zealand

\subsection{6/bmjspcare-2018-hospiceabs.291}

Background Specialist palliative care services in New Zealand expects registered nurses to be practicing at a 'proficient' or 'expert' level. The evidence for this is through a collection of documentation and appraisals gathered as a professional portfolio. A review of nurses within the organisation uncovered a lower than expected percentage who currently hold a portfolio. A study has been undertaken to research nurses' current understanding of these levels of practice and perceived barriers and benefits.

Aims To ascertain nurses' understanding of the process involved in creating a portfolio and their perceived benefits and barriers around this process. As this is a contractual condition it is important to identify issues and reticence so that as an organisation these can be addressed and nurses are able to demonstrate their clinical competence. These benefits and barriers would then be benchmarked at similar organisations nationally. Method Approval for this study was necessary from the Clinical Development Specialist, Clinical Manager, Human Resources and Chief Executive Officer, as questionnaires were sent to all nursing staff. These were sent both electronically and also as hard copies. The information was then collated to identify common themes and issues which arose. As part of the study other hospices were then contacted to circulate the questionnaires to nursing staff so comparisons and benchmarking could be completed.

Results Results are still being collated at time of writing. The response rate has been encouraging with a current return rate of between $30 \%-40 \%$ of nurses responding.
Conclusion From the original organisational results we have found definite gaps in understanding of what the different levels of practice are, as well as some commonly perceived barriers. These initial findings will be presented to the management levels by late July 2018 and the results from across New Zealand should be reportable by early September 2018.

\section{P-267 'THERAPY REVOLUTION': NHS ROTATIONAL THERAPY POSTS IN A HOSPICE SETTING}

Helen Birch. Queenscourt Hospice, Southport, UK

10.1136/bmjspcare-2018-hospiceabs.292

Background Recruiting and retaining therapists has been challenging and expensive, with few therapists with specialist palliative care knowledge and skills and many choosing to practise within their own area of expertise. Agency staff were utilised and although knowledgeable and professional, didn't take ownership of the role and cost was prohibitive. We needed to be innovative in order to develop, recruit and retain therapy staff and ensure that the wider therapy workforce gains palliative care knowledge. We have a proven track record developing roles from within and excellent collaborative working with the local NHS Hospital Trust.

Aims To ensure the organisation evolves to meet the needs of the local population (NICE guidelines for care of the dying, 2015; Ambitions for palliative and end of life care, 2015) and give therapists the experience of working in a specialist palliative care organisation for a defined period, enabling them to utilise their new found skills in practice when returning to the hospital, ultimately providing a wider recruitment pool in future.

Methods Formal discussions between hospice clinical leads and head of therapy services in the local NHS Trust to determine interest and costings for a mutually beneficial collaboration. Proposal paper presented to hospice Board of Trustees for discussion and approval.

Results Approval given for the hospice to form part of the wider NHS Trust therapy rotation programme. Therapists rotated to the hospice would be supported and mentored by the hospice therapy lead and clinical team.

Conclusion We continue to strengthen relationships working collaboratively with the hospital trust and sharing good practice, not only are we creating a workforce with experience, specialist knowledge and skills in palliative care for recruitment purposes for the future, but those therapists who have spent time at the hospice are utilising their new skills in their general practice, undertaking audit and education sessions, so benefiting every patient they care for, wherever that may be.

\section{P-268 IS STRESS, COMPASSION FATIGUE AND/OR BURNOUT PREVENTABLE IN HOSPICE NURSES?}

Niamh Eve. St. Helena Hospice, Colchester, UK

10.1136/bmjspcare-2018-hospiceabs.293

Background Stress, compassion fatigue and/or burnout can be destructive to a nurse's health and career (Ablett \& Jones, 2007). It has been identified that hospice nurses face many stressors, but some research has identified that they do not 